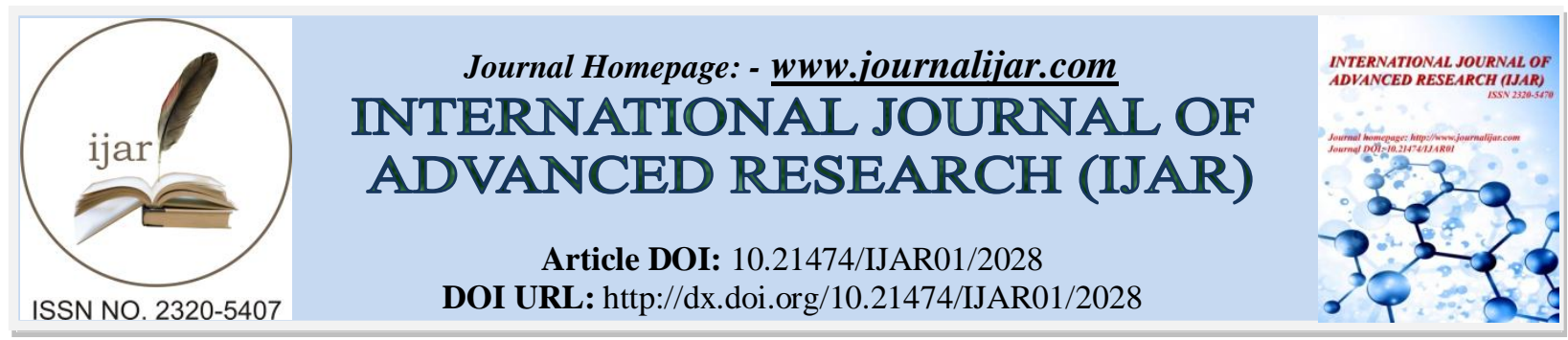

RESEARCH ARTICLE

\title{
PSYCHOLOGICAL EFFECTS CREATES THE CRIME PREVENTION STRATEGIES IN RACE OF MODERN IN INDIA.
}

K.Ravichandran and Dr.S.Arulchelvan.

Department of Media Science, Anna University, Sardar Patel Road, Chennai-600025 Tamil Nadu, India.

\section{Manuscript Info}

Manuscript History

Received: 25 September 2016

Final Accepted: 9 October 2016

Published: October 2016

\section{Abstract}

Conversely, some exploration has found the rates of savagery executed by men and ladies against their accomplices to be of comparable size .Abusive behavior at home is connected with a scope of wellbeing issues and is the single greatest wellbeing danger to Indian ladies matured 15 to 44 years. This study has blended discoveries as for the nature and pervasiveness of physical and sexual viciousness against ladies from socially and semantically distinctive foundations. Abusive behavior at home alludes to demonstrations of brutality that happen inside personal connections and occur in local settings. This rundown paper gives a brief outline of this range of examination. Sexual brutality is any sexual demonstration, endeavor to acquire a sexual demonstration, or other act coordinated against a man's sexuality utilizing intimidation, by any individual paying little mind to their relationship to the casualty, in any setting.

Copy Right, IJAR, 2016,. All rights reserved.

\section{Introduction:-}

Abusive behavior at home alludes to demonstrations of brutality that happen inside personal connections and occur in local settings. Sexual brutality is any sexual demonstration, endeavor to acquire a sexual demonstration, or other act coordinated against a man's sexuality utilizing intimidation, by any individual paying little mind to their relationship to the casualty, in any setting. Interestingly, as age increases psychological vulnerability decreases. Plus, even ladies are quick understanding that they are in charge of their security. This is keeping in perspective of the expanding number of wrongdoings against ladies in transports and taxis in the city which is frequently alluded as assault capital of the nation (Discrimination, Inequality, and Poverty-A Human Rights Perspective- 2016).

One of the key reasons is threatening nature of police power, to a great extent commanded by men. Conversely, some exploration has found the rates of savagery executed by men and ladies against their accomplices to be of comparable size. Abusive behavior at home is connected with a scope of wellbeing issues and is the single greatest wellbeing danger to Indian ladies matured 15 to 44 years (Naomi Gryn(2012). This study has blended discoveries as for the nature and pervasiveness of physical and sexual viciousness against ladies from socially and semantically distinctive foundations.

As age increases recognition of physical cues decreases. Haryana's abutting Delhi, India's national capital, additionally wants to dispatch an all-ladies taxi administration. In India an assault happens like clockwork in India, as per National Crime Records Bureau. In the year 2011, there were 228,650 such episodes were accounted for from 
different parts of the nation. That is the reason practically every state in Indian is taking a shot at the Idea of all ladies police headquarters.

The report further said that there were an aggregate of 244,270 episodes of wrongdoing against ladies were accounted for the year, just about one occurrence at regular intervals. The report further said that there were a sum of 244,270 episodes of wrongdoing against ladies was accounted for the year, just about one occurrence at regular intervals. "The progression guarantees a situation helpful for courageous reporting and touchy examination of violations against ladies by just ladies cops keeping an eye on one ladies police headquarters in each area," (Haryana Director General of Police Singhal). Sociologists say that violations against ladies are high in Northern part of the nation, however more often than not they go (Times of India-2016).

As a consequence, fear of terrorism and fear of crime are becoming interlinked in the general public mind. A gathering called, Red Brigade, shows young ladies how to shield themselves from aggressors in Lucknow in Northern India (Paul Armstrong-2013). Private accomplice and sexual viciousness are generally executed by men against ladies. Nation's National Crime Records Bureau of India in a report said that wrongdoing against ladies saw an expanded 6.4\% amid the year 2012.In the most recent couple of months no less than two occurrences were accounted for where taxicab drivers purportedly assaulted the female rider. Protection reputedly secures our protection, and however we preserve to enjoy insecure the greater safety we cozy (Lee, 2007).

\section{Review of literature:-}

Abusive behavior at home alludes to demonstrations of brutality that happen inside personal connections and occur in local settings. Abusive behavior at home acquires huge social, enthusiastic and financial expenses to casualties, their families and the more extensive group (Laing and Bobic 2002).

This rundown paper gives a brief outline of this range of examination. Abusive behavior at home is generally connected with instances of physical brutality happening inside close connections and in a local setting. Exploitation overviews are an imperative wellspring of data on the nature and degree of aggressive behavior at home on the grounds that the rate of reporting for abusive behavior at home occurrences is low. It is generally acknowledged that aggressive behavior at home is all the more regularly executed by guys and that ladies will probably endure physical mischief on account of their accomplice (Taft, Hegarty and Flood 2001;).

Conversely, some exploration has found the rates of savagery executed by men and ladies against their accomplices to be of comparable size (Headey, Scott and de Vaus 1999). Talk about with respect to the rates of viciousness against men conferred by ladies in personal connections still exists, and there has been a developing group of examination into the nature and commonness of male exploitation and abusive behavior at home in gay person connections. Be that as it may, ladies who are brutal will probably be driven by dissatisfaction and outrage as opposed to by a particular goal, and their viciousness will probably be submitted in self preservation, or in striking back to incitement (James, Seddon and Brown 2002; Tomison 2000).

Abusive behavior at home is connected with a scope of wellbeing, Research has distinguished that numerous casualties see the passionate effects of both physical and non-physical misuse, for example, their level of apprehension, their accomplice's goal to hurt and their own particular self fault-as being more critical than any physical wounds caused (Flood and Fergus 2008). The commonness, seriousness and type of aggressive behavior at home, access to administrations and ability to leave rough connections varies inside a group, with specific gatherings more helpless than others. Indigenous ladies are over-spoken to as casualties of abusive behavior at home, with exploitation rates evaluated to be much higher than those of non-Indigenous ladies (Indermaur 2001; Mouzos and Makkai 2004; NCRVWC 2009a). A key issue keeping Indigenous ladies from getting to guiding, lawful and restorative bolster administrations is the closeness and expansiveness of family relationship bunches."

Ponders have created blended discoveries as for the nature and pervasiveness of physical and sexual viciousness against ladies from socially and semantically distinctive. Research has demonstrated that ladies are more averse to report aggressive behavior at home exploitation to police or to get to standard administrations in view of recognition that these administrations would not comprehend their specific circumstance and react properly (WA Department for Communities 2006). 
The ABS Personal Safety Survey recognized that ladies might be at expanded danger of aggressive behavior at home amid pregnancy. More seasoned ladies experience savagery and misuse at a rate over two times higher than more established guys (Boldy et al. " Adults are the customary demographic gathering most normally connected with aggressive behavior at home, however the predominance of viciousness in youthful connections has gotten more consideration as of late. Young ladies are more probable than youthful guys to be subjected to mental, sexual and physical brutality executed by their beaus or companions.

In any case, bolster benefits and long haul arrangements might be less promptly accessible to youngsters who are casualties of aggressive behavior at home. There is no single cause or component that prompts aggressive behavior at home.

Different situational components, while not immediate causes, may build the danger of abusive behavior at home. Liquor is a noteworthy danger element for abusive behavior at home, with exploration proposing that ladies whose accomplices regularly devour liquor at extreme levels will probably encounter brutality (Marcus and Braaf 2007; Mouzos and Makkai 2004). There is solid proof of a relationship between substantial drinking and animosity (Wells and Graham 2003).

Research has found that, subsequent to controlling for different components, there are higher rates of abusive behavior at home in those family units in which there are kids present (Romans et al). Systems to beat these obstructions are important to guarantee that casualties, especially those inside the most defenseless gatherings, can get to bolster administrations to diminish the danger of brutality. All together for these techniques to be successful, it is critical that lessons from past projects are noticed and the usage issues depicted above are tended to.

Sexual brutality is "any sexual demonstration, endeavor to acquire a sexual demonstration, or other act coordinated against a man's sexuality utilizing intimidation, by any individual paying little mind to their relationship to the casualty, in any setting. A later examination of WHO with the London School of Hygiene and Tropical Medicine and the Medical Research Council, in light of existing information from more than 80 nations, found that all inclusive $35 \%$ of ladies have encountered either physical and/or sexual personal accomplice savagery or nonaccomplice sexual viciousness. Private accomplice and sexual viciousness are generally executed by men against ladies.

Variables connected with personal accomplice and sexual savagery happen at individual, family, group and more extensive society levels. The social and monetary expenses of cozy accomplice and sexual viciousness are colossal and have gradually expanding influences all through society. Right now, there is couple of mediations whose adequacy has been demonstrated through very much outlined studies. As to avoidance, there is some proof from high-wage nations that school-based projects to counteract brutality inside dating connections have demonstrated viability.

\section{Participants:-}

Thirty two respondents took part in this studies, drawn from an opportunity sample of citizens from diverse geographical areas inside Chennai city in Tamil Nadu. All individuals were approached between 9.00am and $5.00 \mathrm{pm}$ over a -day period in May2015. The sample comprised 192 male and 158 woman individuals, aged between 18 and 75 years. The mean age was 2.23. This kind of convenience sampling layout has been criticized due to the fact of its obstacles in terms of generalizability of results. but, the researcher decided that this method become good enough, as it allowed to get right of entry to a large pattern of population without problems and it can also be quick. All contributors who agreed to take element gave earlier knowledgeable consent.

\section{Method:-}

A pilot examine was undertaken on a organization of volunteers who were comparable to the goal population, to identify any sensible troubles in the following studies manner. The remarks confirmed that the questionnaire become straight forward and smooth to complete. Therefore no amendments or changes had been required to the layout. The questionnaire proved to be a seasoned format. 


\section{Results:-}

"Never could an increase of comfort or security be a sufficient good to be bought at the price of liberty" Belloc, $1870-1953$

Table 1:- Central tendency and dispersion of vulnerability scores.

Report: psychological vulnerability

\begin{tabular}{|l|l|l|l|l|}
\hline Gender & Mean & $\mathrm{N}$ & Std. Deviation & \% of Total N \\
\hline Male & 1.74 & 192 & .437 & $54.9 \%$ \\
\hline Female & 1.72 & 158 & .453 & $45.1 \%$ \\
\hline Total & 1.73 & 350 & .444 & $100.0 \%$ \\
\hline
\end{tabular}

Table: 1 Demonstrates that there is no consistent difference in the vulnerability scores for females and males. Interestingly males score higher for vulnerability than females which is unexpected.

Table 2:- Central tendency and dispersion scores.

\section{Report: Physical Cues Score}

\begin{tabular}{|l|l|l|l|l|}
\hline Gender & Mean & $\mathrm{N}$ & Std. Deviation & \% of Total N \\
\hline Male & 1.21 & 192 & .411 & $54.9 \%$ \\
\hline Female & 1.25 & 158 & .433 & $45.1 \%$ \\
\hline Total & 1.23 & 350 & .421 & $100.0 \%$ \\
\hline
\end{tabular}

Table two demonstrates that there is a wider spread between females and males for awareness of physical cues.

Graph 1:-

\begin{tabular}{|c|c|c|c|}
\hline \multicolumn{4}{|c|}{$\begin{array}{c}\text { Females and males recognition of physical cues } \\
\text { and psychological vulnerability }\end{array}$} \\
\hline \multirow{5}{*}{$\begin{array}{r}2500 \\
2000 \\
1500 \\
1000 \\
500 \\
0\end{array}$} & \multicolumn{3}{|l|}{ حـ } \\
\hline & \multirow{3}{*}{\multicolumn{3}{|c|}{$\underbrace{*}_{1}$}} \\
\hline & & & \\
\hline & & & \\
\hline & Sum & $\mathrm{N}$ & Mean \\
\hline $\begin{array}{c}\text { - psychological vulnerability } \\
\text { Total }\end{array}$ & 606 & 350 & 1.73 \\
\hline $\begin{array}{c}\text { * psychological vulnerability } \\
\text { Female }\end{array}$ & 271 & 158 & 1.72 \\
\hline $\begin{array}{c}* \text { psychological vulnerability } \\
\text { Male }\end{array}$ & 335 & 192 & 1.74 \\
\hline -Physical Cues Score Total & 430 & 350 & 1.23 \\
\hline$\rightarrow$ Physical Cues Score Female & 197 & 158 & 1.25 \\
\hline$\sim$ Physical Cues Score Male & 233 & 192 & 1.21 \\
\hline
\end{tabular}

This Graph 1 shows no consistent pattern between females and males recognition of physical cues and feelings of psychological vulnerability. 
Graph 2:-

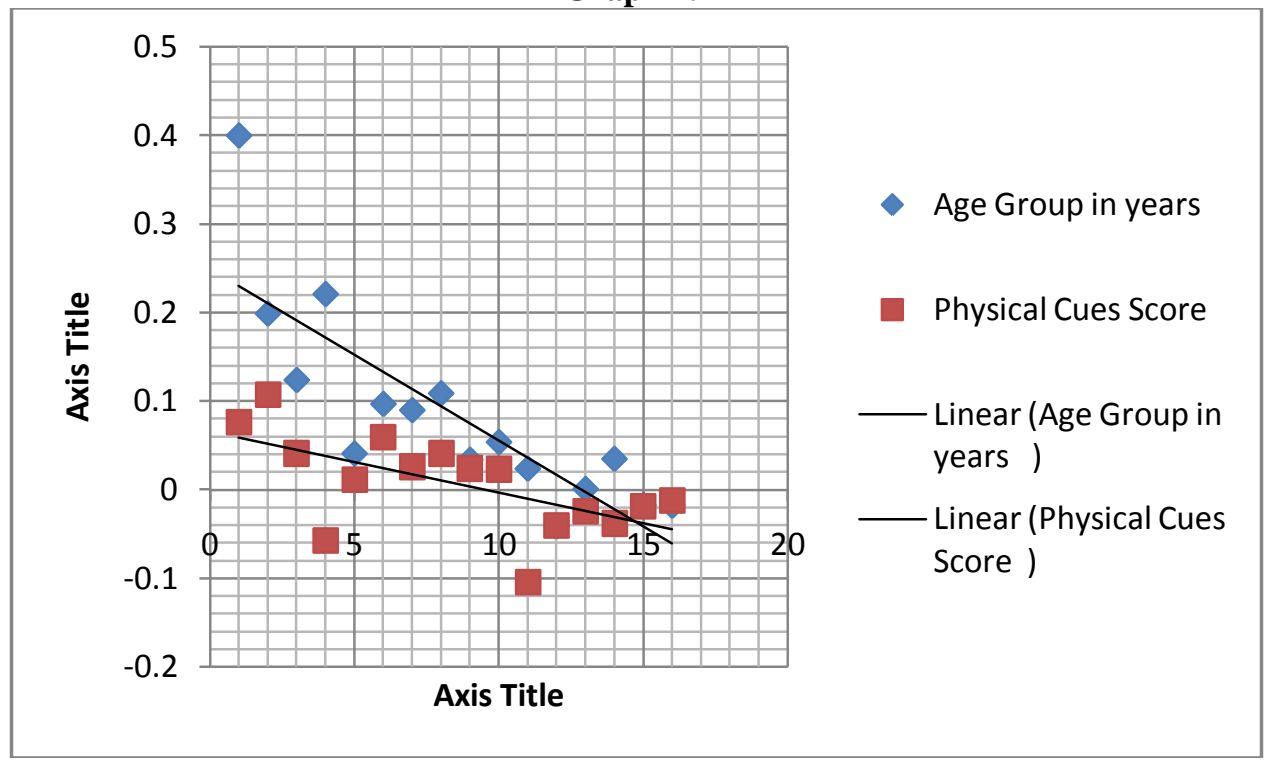

This graph2 shows a negative correlation between physical cues and age. As age increases recognition of physical cues decreases.

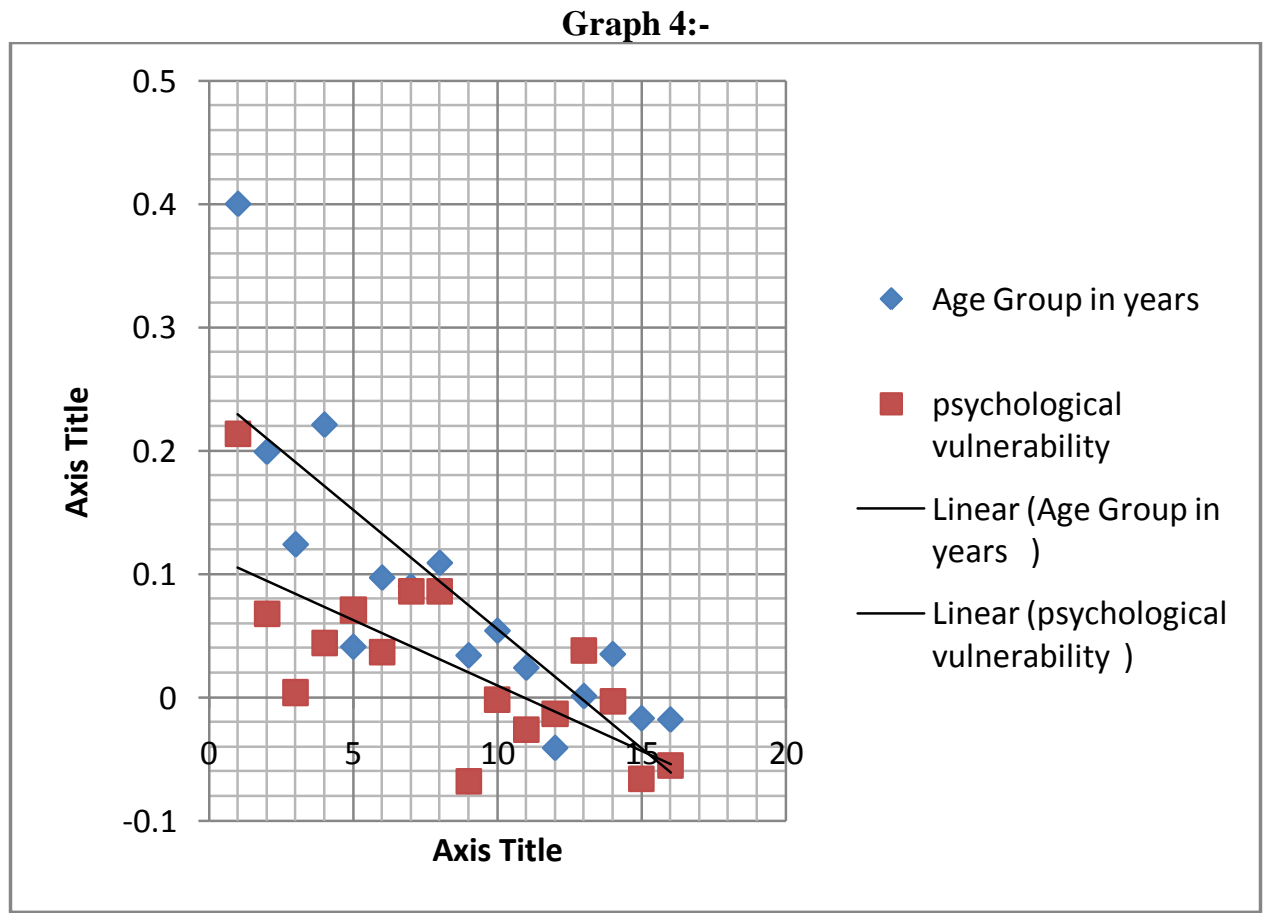

This graph 3 shows a negative correlation between age and psychological vulnerability. Interestingly, as age increases psychological vulnerability decreases. 


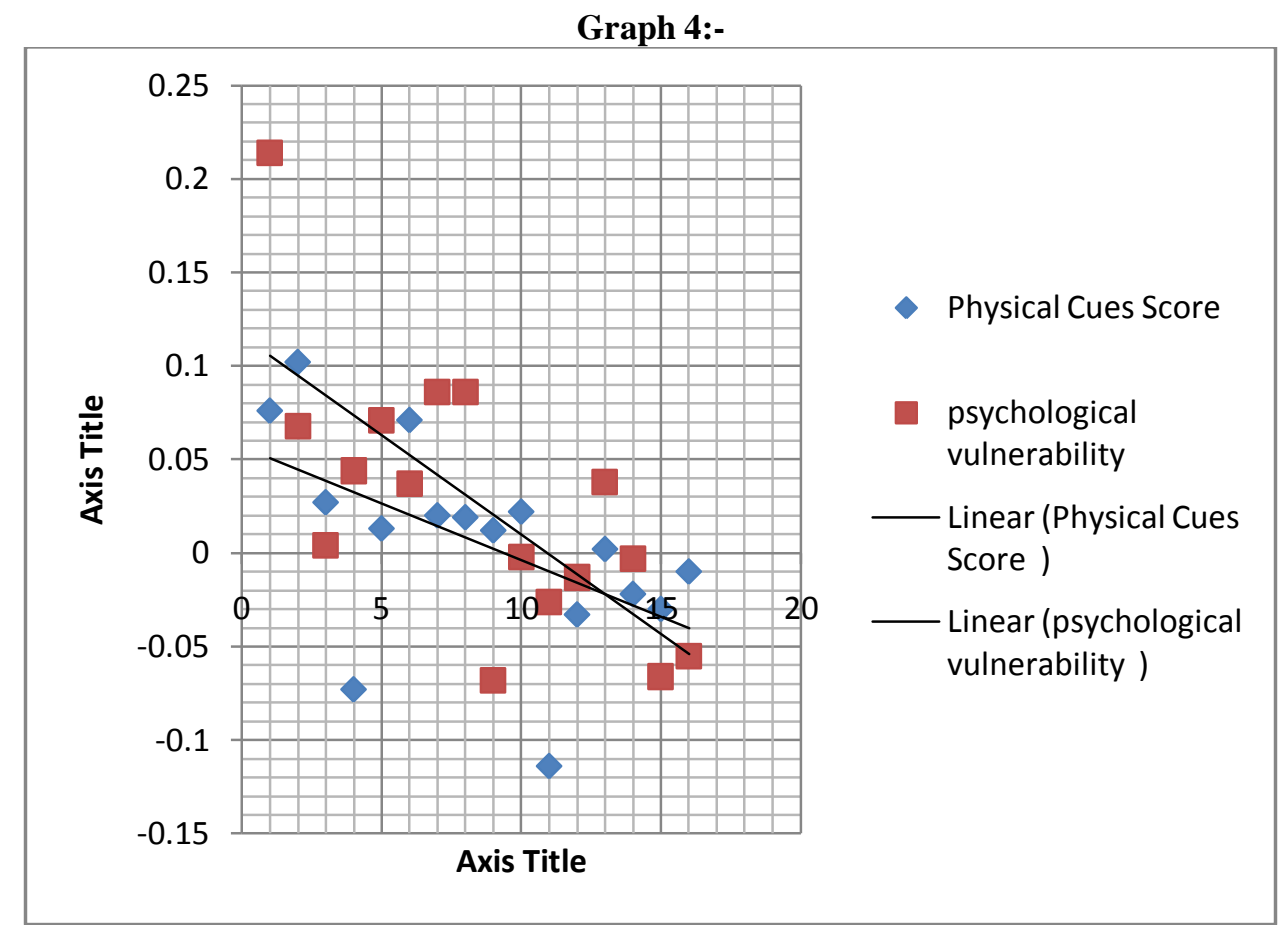

This graph4 shows a positive correlation between physical cues and psychological vulnerability.

\section{Hypothesis:-}

"No passion so effectively robs the mind of its powers of acting and reasoning as fear. "Edmund Burke, 1729-1797

\section{Hypothesis 1:-}

A factual examination was utilized to check the connection among mental helplessness and substantial prompts. Since the data was transformed into c programming dialect, and the specimen changed into illustrative of the objective populace, the register utilized changed with parametric, along these lines a Normative $\mathrm{Z}$ esteem changed into utilized. The ascertained estimation of get has to be - 11.852; the reproachful of relevant worth get to be zero.001**. As the figured expense was more than the significant worth, the theory is standard.

\section{Hypothesis 2:-}

A measurable investigation was utilized to investigate the relationship amongst age and substantial signals. As the records got to be interim, and the example got to be illustrative of the objective populace, the test utilized transformed into parametric, in this manner Normative $\mathrm{Z}$ esteem changed into utilized. The ascertained estimation of get to be - 11.852; the reproachful of relevant worth get to be zero.001**. As the figured worth got to be handiest more than the essential expense to $\mathrm{p}=0.2$, the hypothesis is rejected.

\section{Hypothesis 3:-}

A factual assessment was utilized to test the association amongst age and mental powerlessness. Since the data changed into c dialect, and the specimen get to be specialist of the objective masses, the check utilized got to be parametric, subsequently along these lines Normative $\mathrm{Z}$ esteem changed into utilized. The ascertained worth transformed into - 4.474; the condemning of critical quality get to be $0.001 * *$. As the ascertained expense was additional than the crucial value, the hypothesis is general.

\section{Hypothesis 4:-}

McNemar Test of Chi-Square was utilized to watch the distinction among grown-up guys and females and their notoriety of physical signals. This changed into chose as the scope of men and ladies in the example had been no more indistinguishable, and the data could be changed to ordinal measurements. The figured estimation of ChiSquare gets to be 37.056 . The estimation of Chi-Square is gotten to be $0.001 * *$. since the computed estimation of 
Chi-Square transformed into very little less or indistinguishable to the critical worth, the invalid theory was ordinary, and the option hypothesis got to be rejected.

\section{Hypothesis 5:-}

McNemar Test of Chi-Square investigate get to be utilized to watch the distinction among grown-up guys and females and their notoriety of mental helplessness. This changed into chose as the scope of men and ladies in the example had been no more indistinguishable, and the data could be changed to ordinal insights. The computed estimation of Chi-Square is gotten to be 50.048. The estimation of Chi-Square is gotten to be $0.001 * *$. since the figured estimation of Chi-Square transformed into very little less or indistinguishable to the critical worth, the invalid theory was ordinary, and the option hypothesis got to be rejected.

\section{Discussion:-}

"We must plan for freedom, and not only for security, if for no other reason than only freedom can make security more secure."

\section{Popper, 1902-1994}

The motivation behind this study is to break down how mental powerlessness shifts reliably with the nearness of neighbor-hood SCP/wellbeing highlights. A wide assortment of Hypothesis with respect to sexual orientation and age has been also investigated. This confirmed the recurrence of defenselessness around non-open assurance transformed into molded by method for subjective quality determinations of the possibility of exploitation. The outcomes demonstrate that being aware of neighborhood efforts to establish safety does not generally diminish fear and may likewise in actuality on occasion blast it. The scientist offers a couple of practical motivations to higher perceive the security/FOC oddity.

The main Hypothesis tried sentiments of mental helplessness and prominence of real prompts and affirmed a fullmeasure connection $(Z=-11.852)$. This got to be foreseen and helps existing studies in this area. Nelson,et.al (2001) found that the nearness of wellbeing screens around the local area focus places uplifted levels of trepidation, more prominent recently, Barbaret and Fisher's' (2009) thinks about uncovered that understudies who are additional mindful of most extreme ,"target solidifying" measures for the most part have a tendency to be additional frightful of robbery. Measurements from the semi-organized meetings gave some recognition into this. Individuals communicated the perspective that zones with an intemperate centralization of efforts to establish safety had been connected with larger amounts of danger. Givers likewise trusted that less well-off locales have been identified with more wrongdoing and sickness.

It isn't generally perfect concerning regardless of whether SCP measures by method for them being development impression of risk of private exploitation. Cutting edge discoveries recommend that distinctive relevant elements, together with SCP measures, help in development of mental weakness. A road connection that comprises of a SCP degree may also add to the effect that a range is perilous.

The second Hypothesis tried the impact of age on distinguishing proof of physical prompts, uncovering no awesome relationship $(Z=-6.087)$. In any case, chart 2 shows that as age expands acknowledgment of physical signs diminish. This in actuality was approved in the meetings. The more established individuals had a tendency to live in prosperous neighborhood with less seen security equipment. Discoveries may likewise furthermore prompt that more seasoned individual's rise as additional acquainted with a region, so overlook beyond any doubt physical signals. Be that as it may, this is a confused issue and is unrealistic to have a solitary illumination.

Hypothesis 3 analyzed the effect of age on mental defenselessness and set up a mammoth relationship ( $Z=-4.474)$. At the same time, chart three shows as age builds, weakness diminishes. Those discoveries negate the former studies highlighting the elderly as the most extreme frightful in the public eye (Ramsay, 1989). This can likewise advocate that more seasoned individuals are less unnerved than more youthful individuals considering by going out substantially less at evening time as an occasion, they might be a great deal less revealed to limit exploitation.

Key elements no doubt to impact apprehension is sentiments of confinement and rejection, genuinely upheld by method for the meetings. In hypothesis 4 male and young lady notoriety of real signals uncovered no tremendous qualification $(\mathrm{p}=0.05)$. The more seasoned people felt there has been more prominent of an ordeal of group and higher degrees of casual observation where they lived. The meetings also affirmed that possibility of exploitation is 
related to a capacity to secure oneself. Proof from the meetings is support that ecological variables play a more enormous capacity. This technique might be an understood response to ecological elements which can show the „"trustworthiness' 'of others whilst making FOC-related examinations. Men inside the example communicated this perspective yet moreover conceded there had been conditions they would maintain a strategic distance from. What's more, the generalizability of those outcomes is constrained to a little number of Blackpool natives. At the point when presenting to all the measurable certainties together for examination, the specialist expressed a greater example that would allow for more noteworthy inductions to be drawn. Hypothesis five likewise uncovered about no boundless qualification in impression of mental helplessness ( $\mathrm{p}=\mathrm{zero} .05)$. These results were sudden as it has been suggested that Fear of Crime is translated in another route organized on sexual orientation (Jefferson and Holloway, 2000). The analyst knew that endeavoring to quantify subjective feelings of powerlessness may exhibit various hindrances. Subsequently, various methodological and definitional boundaries have been highlighted in this which could serve to tell fate research. Predetermination ponders need to look at which parts of the surroundings people at first notice and why, expanding the rundown for measures of significance.

\section{Conclusion:-}

Abusive behavior at home alludes to demonstrations of brutality that happen inside personal connections and occur in local settings. Sexual brutality is any sexual demonstration, endeavor to acquire a sexual demonstration, or other act coordinated against a man's sexuality utilizing intimidation, by any individual paying little mind to their relationship to the casualty, in any setting. This study has blended discoveries as for the nature and pervasiveness of physical and sexual viciousness against ladies from socially and semantically distinctive foundations. Conversely, some exploration has found the rates of savagery executed by men and ladies against their accomplices to be of comparable size .Abusive behavior at home is connected with a scope of wellbeing issues and is the single greatest wellbeing danger to Indian ladies matured 15 to 44 years.

\section{High-profile perfumer Monika Ghurde found murdered in Goa flat:-}

Interestingly, as age increases psychological vulnerability decreases. Conversely, some exploration has found the rates of savagery executed by men and ladies against their accomplices to be of comparable size .Abusive behavior at home is connected with a scope of wellbeing issues and is the single greatest wellbeing danger to Indian ladies matured 15 to 44 years .this study has blended discoveries as for the nature and pervasiveness of physical and sexual viciousness against ladies from socially and semantically distinctive foundations. As age increases recognition of physical cues decreases. The calculated value of Chi-Square becomes 37.056. All at once, graph three shows as age increases, vulnerability decreases. In India an assault happens like clockwork in India, as per National Crime Records Bureau. The gathering individuals are constantly wearing red and dark. This became anticipated and helps existing studies in this location. The calculated value of become -11.852; the critical of significant value become $0.001 * *$.Variables connected with personal accomplice and sexual savagery happen at individual, family, group and more extensive society levels. Hypothesis five likewise uncovered about no boundless qualification in impression of mental helplessness $(\mathrm{p}=0.05)$.

\section{References:-}

1. Discrimination, Inequality, and Poverty-A Human Rights Perspective2013 <https://www.hrw.org/news/2013/01/11/discrimination-inequality-and-poverty-human-rights-perspective>.

2. Naomi Gryn. (2012). Why I'm having my first baby at 51 Life and style | The Guardian. https://www.theguardian.com/lifeandstyle/2012/nov/09/having-first-baby-at-51.

3. NCRB data and analysis of Arrests in 498A and Suicide of Married (2013). Retrieved on October 8, 2016, from http://savefamily.in/158-ncrb-data-and-analysis-of-arrests-in-498a-and-suicide-of-married-men.html.

4. legal rights that women should know. (2016)., from http://timesofindia.indiatimes.com/lifestyle/relationships/man-woman/10-legal-rights-that-women-should-know/articleshow/50742542.cms.

5. Paul Armstrong.(2013) Meet India's Red Brigade: The teens fighting back against rape, CNN,Updated 1121 GMT (1921 HKT) August 14, 2013

6. Laing L and Bobic N (2002) Economic Costs of domestic violence: Literature Review, Australian Domestic and Family Violence Clearinghouse, University of New South Wales, Sydney, April.

7. Taft A, Hegarty K \& Flood M 2001. Are men and women equally violent to intimate partners? Australian and New Zealand Journal of Public Health 25(6): 498-500 
8. Headey, B, Scott, D \& de Vaus, D, 1999, "Domestic Violence In Australia: Are Women And Men Equally Violent"? in International Social Science Surveys Australia, Vol. 2,No. 3

9. James K, Seddon B \& Brown J 2002. 'Using it' or 'losing it': Men's constructions of their violence towards female partners. Sydney: Australian Domestic \& Family Violence ClearingHouse. http://www.austdvclearinghouse.unsw.edu.au/PDF

10. Flood, M \& Fergus, L 2008, An Assault on Our Future: The impact of violence on young people and their relationships, White Ribbon Foundation, Sydney.

11. Indermaur D 2001. Young Australians and domestic violence. Trends \& Issues in Crime and Criminal Justice no. 195. Canberra: Australian Institute of Criminology. http://www.aic.gov.au/publications/current series/tandi/181-200/tandi195.aspx

12. Mouzos J \& Makkai T 2004. Women's experiences of male violence: Findings from the Australian component of the international violence against women survey (IVAWS). Research and public policy series no. 56. Canberra: Australian Institute of Criminology. http://www.aic.gov.au/publications/current series/rpp/4160/rpp56.aspx

13. National Council to Reduce Violence against Women and their Children (NCRVWC) 2009a. Background paper to time for action: The National Council's plan for Australia to reduce violence against women and their children, 2009-2021. Canberra: Australian Government.http://www.fahcsia.gov.au/sa/women/pubs/violence/np_time_for_action/background/Pages/default .aspx

14. WA Department for Communities 2006. A review of literature relating to family and domestic violence in culturally and linguistically diverse communities in Australia. Perth: Department for Community Development. http://www.communities.wa.gov.au/NR/rdonlyres/F99C99BA-66BB-47A4-A2F2-

C9A73AE360F1/0/CaLDliteraturereview.pdf

15. Hilaire Belloc (1870-1953),http://www.catholicauthors.com/belloc.html

16. Nelson, A. G., Guillory, I. K., Cornwell, A., \& Kokonen, J.(2001b). Inhibition of maximal voluntary isokinetic torqueproduction following stretching is velocity specific. Journal of Strength and Conditioning Research, 15, $241-246$ 